\title{
Constructing New Strategies for Combining University Physical Education and Health Education
}

\author{
Xinyu Lian ${ }^{1}$ and Xiadi Lyu ${ }^{2, *}$ \\ ${ }^{1}$ Department of Physical Education, Taiyuan Normal University, Taiyuan, China \\ ${ }^{2}$ Department of Physical Education, Taiyuan Normal University, Taiyuan, China \\ ${ }^{*}$ Corresponding author. Email:15503512467@163.com
}

\begin{abstract}
High education is an important period for college students to mature physically and mentally and form healthy habits. In recent years, colleges and universities around the country have been promoting health education and improving students' knowledge of health. Such efforts have made notable progress. However, in the current implementation of the integration of physical education and health education, there are issues such as non-comprehensive content coverage, lack of targeted population, and missing implementation. This paper uses the method of literature review to analyze and sort out the existing data on the subject. The research shows that the effective integration of physical education and health education can be accomplished through three approaches: physical education instruction system, campus sports activities, and increasing school health education resources. Through research on the concept of physical education and health education, within the current curriculum construction of colleges and universities, this paper explores an integration pathway between the two approaches and provides new ideas for the reformation of physical education and health curriculum which facilitates students' physical health in China.
\end{abstract}

Keywords: University, Physical Education, Health Education

\section{THE NECESSITY OF INTEGRATION OF PHYSICAL EDUCATION AND HEALTH EDUCATION}

From the perspective of concept, physical education and health education are two relatively independent concepts. However, based on the understanding of the essence of school education, both of them serve for students' health in function and are closely related in task objectives. In the process of physical education, students are the main body of activities, with the characteristics of group, entertainment and competition. Health education focuses on rational preaching, with thinking activities as the main activity mode, and students are mainly passive participation. In the nature of curriculum, there are obvious differences between physical education and health education, but they have the same goal in promoting students' physical and mental health, and the differences between them just form a complementary relationship.

\subsection{Policy support for the integration of physical education and health education}

In June 1999, The Decision of the CPC Central Committee and the State Council on Deepening Education Reform and Comprehensively Promoting Quality Education points out: "school education should establish the guiding ideology of 'health first' and reinforce the foundation of physical education[1]." In 2007, the CPC Central Committee and the State Council issued the "opinions of the CPC Central Committee and the State Council on strengthening youth sports and enhancing youth physique" (ZF [2007] No. 7), which also put forward clear requirements for health education: "actively carry out disease prevention, scientific nutrition, health and safety, drug control and tobacco control and other youth health education, and to ensure the necessary time spent on health education. According to the characteristics of adolescence and the psychological characteristics in the process of growth of teenagers in the new period, we should focus on strengthening psychological health education. It shows that the integration of physical education and health 
education has been highly valued by the party and the government. In addition, relevant studies believe that the integration of the two is essentially an exploration of the integrated path of physical education curriculum and health education and is an inevitable requirement for physical education teaching to achieve its sustainable development [2].

\subsection{Physical education is an important part of school health education}

Both physical education and health education put the student body as the objective. While the former aims to improve the health of students, the latter is to maintain holistic health [3]. Therefore, health education should be incorporated into physical education and teaching. Although school physical education has many goals and is multi-level and multi-function, it cannot address all the issues with the current health education on college campuses. As an indispensable and important carrier of school health education, school physical education is not only an important content of school health education and an important means, and its significance is irreplaceable by other disciplines.

\subsection{An important way to improve the health level and health literacy of college students in China}

There are still many health problems in college students in China, such as insufficient sleep, an unbalanced diet, and increased obesity rate, a lack of physical exercise, and so on. Many unhealthy lifestyles have seriously affected the physical health of college students [4]. One of the important ways to solve the problem of students' physique, is to guide students to pursue independent physical exercise and a healthy lifestyle. The integration of school physical education and health education is indispensable in the process of students' forming good living habits and cultivating the drive to participate in the independent exercise. Therefore, how the integration of school physical education and health education is realized is a major practical problem to be solved in improving the health level and health literacy of college students.

\subsection{The inevitable choice to realize the great Chinese dream}

Entering the New Era, not only the society has entered a new period of historical development, but the country is also closer to realizing the dream of the great rejuvenation of the Chinese nation. In order to achieve the "Chinese dream", we must first achieve the "health dream", as having a healthy body and mind is the foundation for the development of all undertakings. "The "Healthy China 2030" Summary program points out that "the national health is the fundamental purpose of building a healthy China [5]." With improved social and economic conditions, social-psychological diseases and mental health problems have a growing impact on people's lives. Therefore, from the student age, it is very important to pay attention to mental health education and improve the mental health of college students. At the same time, the great healthy society dream also requires universities to strengthen physical education and health education, to establish and improve college students' mental health, improve their interpersonal skills, and promote them to form an optimistic and positive attitude towards life.

\section{CURRENT SITUATION OF INTEGRATION OF PHYSICAL EDUCATION AND HEALTH EDUCATION}

In recent years, the development of health education in college physical education has achieved certain results, health education in physical education is also developing in depth. But the fact cannot be ignored is that the implementation of health education in college physical education is still facing many problems and challenges. After research, the current situation of the integration of physical education and health education mainly exists in the following three aspects.

\subsection{The coverage of health education in physical education is small}

Under the modern health concept, the physical education teaching mode should be changed from the previous isolated and single form to a more diversified direction, with students as the main body to comprehensively study the existing problems in all aspects. It is found that, the focus of college physical education teachers is mainly on practical teaching, while the teaching of ideologies of health education is less prevalent [6]. In this way, the University Health Education for students regarding their own health knowledge needs, health foundations, and emotional experiences is lacking. At the same time, the focus of teaching is mainly on sports theory, sports skills, and physical fitness exercises, while the coverage of real health education in sports teaching is focused to a lesser degree. This imbalance affects the integration of physical education and health education [7].

\subsection{The content of health education is weak in physical education}

At present, physical education teachers are largely influenced by the subject center and have a lack of awareness of holistic health education [8]. They often only know and understand physical education from the traditional competitive sports perspective. Most physical education teachers equate the teaching of health knowledge with health education, however, typically have a lack of effort in targeted intervention for 
students, neglecting the cultivation of students' health awareness, behavior, and lifestyle. As the result, health education, which is incorporated in physical education, is in disorder. And the content selection of health education lacks pertinence and directivity [9].

\subsection{The integration of physical education and health education is not comprehensive}

The combination of physical education and health education can be implemented. In the aspect of integration, we should focus on students' physique, mental health and social adaptability, cultivate students' health awareness and lifestyle, and form healthy living habits. However, in the process of college physical education teaching, there are still some deficiencies in the selection of teaching content, teaching organization form, application of teaching methods and teaching evaluation. For example, in the aspect of teaching management, most schools adopt the modular approach to carry out health knowledge teaching in the theoretical class, Only a few schools combine health knowledge teaching with physical education practice teaching; The selection of teaching content, teaching organization and teaching methods are still influenced by traditional teaching, which weakens the teaching effect of health education in physical education.

\section{OPTIMIZATION STRATEGY OF THE INTEGRATION OF PHYSICAL EDUCATION AND HEALTH EDUCATION}

The implementation of the guidelines for health education in Colleges and universities has increased the content of physical health education, but there is no mature experience in all aspects of health education, especially in the penetration of physical education. More schools even rarely carry out the teaching of physical health theory, especially for how to set up a good health education. Therefore, it is of great significance to clarify the specific implementation ideas and explore the main teaching strategies of implementing health education in physical education, so as to effectively promote the implementation effect of health education, improve the physique and health level of college students, and promote their all-round development.

\subsection{Integrating into the teaching system of Physical Education}

In the process of combining the sports practice sector with the health knowledge, it is necessary to realize the reasonable integration of the two independent subsystems, which should not only be accepted by students and promote their participation in learning but also be considered as forming a system of knowledge to present completely and comprehensively [10]. Therefore, in order to integrate health education knowledge into physical education teaching, we should take the Guidelines for Health Education in Colleges and Universities as the guidance. We would determine the core teaching content, take the contents involved and required in the guidelines as the teaching focus, and integrate them into the physical education teaching system. We could make the health education knowledge and sports skills practice go hand in hand with each other in the process of learning, to ensure the healthy development of students [11].

\subsection{Integrating into campus sports activities}

Campus sports activity is one of the main ways of college students complete their daily physical exercise. Integrating health education into campus sports competitions and other sports activities can further implement the concept of holistic health and help students to develop good sports habits. Colleges and Universities can plan and implement sport activities based on their regional characteristics, campus facilities, and other external resources. Schools should focus on cultivating students' understanding and experience of sports when they participate in various sports activities. Students can plan and organize sports activities according to the theme of health education [12]. It emphasizes that students should have control over the time and intensity of their physical exercise and pay attention to the arrangement of relaxation activities and diet after exercise [13]. Moreover, such form of physical education should also pay attention to students' emotional experience in sports activities, and cultivate students' passion for sports, respect for rules, willingness to cooperation, and unafraid of hurdles, as well as other virtues.

\subsection{Increasing school health education resources}

In addition to improving facilities, equipment, places, expanding the sources of funding channels and other conventional practices, we must increase the proportion of health education content in school physical education, actively develop health education courseware, graphic materials, and health prescriptions and exercise prescriptions for students' myopia, scoliosis, and other prominent problems [14]. We should also stablish a school health education curriculum resource database. Furthermore, through the construction of a health education website and information platform for college students' health promotion and guidance, we can provide necessary health service support for students' independent participation in health intervention activities.

\section{Conclusion}

In recent years, colleges and universities across the country have done a lot of work in promoting health education and improving students' health literacy, and made positive progress. In the current implementation of the integration of physical education and health 
education, there are many problems such as the coverage of health education is not wide, the direction is not strong, and the measures are not in place. At present, the development of health education still needs to take school physical education as the carrier and penetrate deeply from all aspects of physical education. Physical education is still the main content. By integrating health education content into physical education teaching system, campus sports activities and educational resources, we can effectively strengthen the penetration of health education content in physical education.

Through the research on the concept of physical education and health education and the current situation of curriculum construction in Colleges and universities, this paper explores the integration path between the two, and provides new ideas for the reform of physical education and health curriculum and the promotion of students' physical health in China.At the same time, it is of great practical significance for the healthy development of students to explore the theoretical logic of the integration development of physical education and health education, examine the necessity of the integration development and explore new ideas and optimization strategies of the integration development.

\section{ACKNOWLEDGMENTS}

This paper cites the research literature of several scholars. Without the help and Inspiration of the research results of scholars, it will be difficult for me to complete this paper. Thank my classmates and friends for giving me a lot of materials in the process of writing my thesis, and also providing warm help in the process of writing and typesetting. Due to my limited academic level, there are inevitably deficiencies in my thesis. I sincerely ask all teachers and students to criticize and correct me.

\section{REFERENCES}

[1] S, YU. Construction of the framework system of Chinese student's physical Education disciplinary core makings. $[\mathrm{J}]$. Journal of Physical Education,2017,24(04):5-9.

[2] Y, FENG\&J.L, LI. (2015). Examination of the relationship between physical education classes and health education. [J]. Journal of Physical Education ,2015,22(02):86-89.

[3] Document A P. Implementation of Grades 11 and 12 Physical Education/ Health Education.

[4] School A. Scheduling Kindergarten to Grade 8 Physical Education/ Health Education.

[5] State Council of the PRC. Outline of "healthy China 2030"[Z].2016-10-25.

[6] Birinci C, S Şahbaz, Erkin A, et al. An assessment of the attitude of the students of Sport Management department towards the departments of Pyhsical Education and Sport Teaching and Coaching Training., 2013.

[7] Sallis J. Ecological model of health behaviour [J]. Health Behavior \& Health Education, 2002.

[8] Ross C E, Willigen M V. Education and the subjective quality of life.[J]. J Health Soc Behav, 1997, 38(3):275-297.

[9] Kickbusch I S. Health literacy: addressing the health and education divide.[J]. Health Promotion International, 2001(3):289-297.

[10] Zhang X, Kanbur R. Spatial inequality in education and health care in China[J]. China Economic Review, 2005, 16(2):189-204.

[11] Guo S H, Qiang F. Health Education and Physical Education[J]. Journal of Kunming Metallurgy College, 2004.

[12] Cook H, Kohl H. Educating the Student Body: Taking Physical Activity and Physical Educati on to School.[M]. National Academies Press. 500 Fifth Street NW, Washington, DC 20001. Tel: 888-624-8373; Tel: 202-334-2000; Fax: 2 02-334-2793; e-mail: Customer_Service@nap.edu ; Web site: http://www.nap.edu, 2013.

[13] Sallis J F, Mckenzie T L , Beets M W, et al. Physical Education's Role in Public Health: Steps Forward and Backward over 20 Years and HOPE for the Future $[\mathrm{J}]$. research quarterly for exercise \& sport, 2012, 83(2):125.

[14] Fairclough, S. 'Physical education makes you fit and healthy'. Physical education's contribution to young people's physical activity levels[J]. Health Education Research, 2005, 20(1):14-23. 